\title{
The Levels of Inner Compatibility According to Over-Engagement of HCI among Korean and Chinese University Students
}

\author{
Jae-Yong Lee, Hae-Ri Park, Cheong-Hwan Lim
}

\begin{abstract}
The objective of this study was to determine whether organizational-level change from interaction with other systems HCI or inner compatibility might be a general characteristic of Northeast Asian college students. Results of 853 adult internet addiction diagnoses (K scale) were recategorized into perceptual, emotional consciousness, subjective consciousness, and cognitive awareness based on integrated information theory for college students in Korea and China. They were then compared to determine changes at organizational levels caused by HCI based on frequency analysis, descriptive statistics, mean difference (t-test), and reliability analysis. Especially, in case of self-awareness, it was confirmed that Korean students were more integrated into feeling of self-awareness irrespective of any physical or social situations than Chinese students. This signifies that HCI over-engagement can affect each layer of the human state of consciousness. Results of this study also imply that HCI dysfunction should be interpreted in terms of over-engagement. This study also confirms that various levels of consciousness are influenced differently. In particular, changes at organizational level of consciousness appeared in both countries. Thus, this could be a general characteristic of Northeast Asian University students. HCI over-engagement affects three levels of consciousness differently. Change at organizational level of consciousness was found to be a general characteristic of college students in Northeast Asia.
\end{abstract}

Keywords: HCI, inner compatibility, consciousness level.

\section{INTRODUCTION}

$W_{\text {ith the development of immersive media technology }}$ that makes computer and internet technology and human sense information mechanically processable with computers, it is possible now to interact with people from all over the world without limitation of space. As a result, human computer interface (HCI) has become widespread as adolescents during the growing period use computer in the process of interacting with the outside[1]. Most studies on computer-human contact problems have focused on adverse effects of HCI on adolescence. However, based on large

Revised Manuscript Received on July 22, 2019.

Jae-Yong Lee, Department of Unmanned Aircraft Systems, Hanseo University(TAean Campus), TAean, Chungcheongnam-do, Republic of Korea. Email: jylee@ hanseo.ac.kr

Hae-Ri Park, Department Health and Environmental Science, Sinseong University, Seosan City, Chungcheongnam-do, Republic of Korea. Email: parkk1225@hanmail.net

Cheong-Hwan Lim*, Department of Radiological Science, Hanseo University, Seosan City, Chungcheongnam-do, Republic of Korea. Email: lch116@hanseo.ac.kr

This study was conducted with the support of the 2019 Hanseo University Intramural Research Support Project. amounts of research results accumulated, a new perspective on HCI dysfunction has been proposed through macroscopic big data analysis. In other words, the fact that pregnancy, violence, and consumption of alcohol and tobacco continue to decline over the past two decades is contrary to the claim that HCI harms youth[2]. In addition, adolescents experiencing difficulties in the virtual world have experienced difficulties in the real world. It has been found that parents with higher incomes have more adequate control the time of HCI than those with lower incomes[3]. Therefore, efforts are being made to describe the process of information transmission in HCI with the concept of compatibility in the information transmission process between human and computer and measure changes in the level of human organization with concept of cybernetics where humans and machines interact with each other. In other words, it is to express and interpret the behavior of humans using computers in terms of statistical mechanics information theory. Researchers have attempted to interpret information as a change in the level of organization that results from interaction of one system with another system by extending it to the concept of physical information[4], [5]. The change here is called negative entropy[6]. Integrated information theory is used by psychologists studying consciousness to interpret human consciousness as a statistical epistemological information[7]. Based on the integrated information theory, consciousness is information that other forms of consciousness are related to at a wide variety of levels[8].

\section{INNER COMPATIBILITY}

The integrated information theory is a concept of statistical mechanics. It describes the state of consciousness by dividing consciousness into seven types as shown in Table- I[9].

However, it is difficult to distinguish the inner processes occurring in human beings into 7 levels of consciousness and measure them as they are. This is because it is impossible for humans to precisely separate their internal consciousness levels and respond to the questionnaire. Thus, these seven types were grouped into three consciousness levels (human perceptual and emotional consciousness, subjective consciousness, and cognitive awareness) as shown in Table- I. Research has been carried out by separating human computer interactions into organizational level changes resulting from interaction [10], [11].

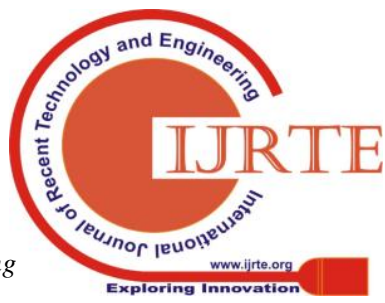




\section{The Levels of Inner Compatibility According to Over-Engagement of HCI among Korean and Chinese University Students}

Previous studies have reported that perceptual and emotional consciousness, subjective consciousness, and cognitive awareness levels are differently influenced by factors that can lead to overdependence of human computer interaction. However, it is currently unclear whether HCI dysfunction based on this statistical mechanistic information theory might be a general characteristic, not unique to Koreans. Therefore, the objective of this study was to examine whether over-engagement in HCI process could affect consciousness levels differently between Korean and Chinese college students. In addition, a comparative study was conducted to determine whether it was reasonable to separate perceptual and emotional consciousness levels, subjective consciousness levels, and self-awareness levels when developing items to measure inner compatibility according to consciousness level. not possible.

Table- I: Classification and measurement of consciousness according to integrated information theory

\begin{tabular}{|c|c|}
\hline Classification of consciousness & $\begin{array}{c}\text { Unit of } \\
\text { measure }\end{array}$ \\
\hline $\begin{array}{l}\text { Information 1: Representation of } \\
\text { physical world through sensory nervous } \\
\text { system - sense }\end{array}$ & \multirow{3}{*}{$\begin{array}{l}\text { Perceptual and } \\
\text { emotional } \\
\text { consciousness } \\
\text { (Sensory } \\
\text { perception) }\end{array}$} \\
\hline $\begin{array}{c}\text { Information 2: A new level of } \\
\text { information delivered to the central } \\
\text { nervous system - perception }\end{array}$ & \\
\hline $\begin{array}{l}\text { Information 3: A function that requires } \\
\text { harmonization of behavior to solve } \\
\text { perceptual uncertainty - emotion }\end{array}$ & \\
\hline $\begin{array}{l}\text { Information 4: Subjective perception } \\
\text { based on emotion }\end{array}$ & $\begin{array}{l}\text { Subjective } \\
\text { consciousness } \\
\text { (Subjective } \\
\text { perception) }\end{array}$ \\
\hline $\begin{array}{l}\text { Information 5: Reflective awareness - } \\
\text { cognition }\end{array}$ & \multirow{3}{*}{$\begin{array}{c}\text { Cognitive } \\
\text { awareness } \\
\text { (self-awareness) }\end{array}$} \\
\hline $\begin{array}{l}\text { Information 6: Self-awareness - abstract } \\
\text { thinking }\end{array}$ & \\
\hline $\begin{array}{l}\text { Information 7: Information or } \\
\text { awareness about self-awareness }\end{array}$ & \\
\hline
\end{tabular}

\section{SUBJECTS AND METHTODS OF STUDY}

A questionnaire classified into levels of consciousness based on the information theory of consciousness previously verified with adult internet addiction diagnostic scale ( $\mathrm{K}$ scale) was used to determine whether a particular signal or stimulus could be measured as a reduction in uncertainty of a recipient.

\section{A.Subjects}

It is necessary to classify three categories so that levels of consciousness could be measured based on the integrated information theory to determine whether changes at organizational level were valid only in Korean students and whether they were general characteristics of Northeast Asian college students including Chinese students. In other words, this study identified difference in over-engagement level of 853 college students in Korea and China to determine whether they were affected differently by organizational level.

B.Test Methods

The Adult Internet Addiction Diagnostic Scale developed by the Internet Addiction Center under the National Information Society Agency is the most widely used self-diagnostic measure called the $\mathrm{K}$-scale. It is a diagnostic tool to measure withdrawal and resistance, daily life disability, and virtual interpersonal orientation. To identify changes at organizational levels resulting from human interaction with computer systems, questionnaires arranged in three measurement units were sent to Korean college students and Chinese college students. Frequency analysis, descriptive statistics, t-test, and reliability analyses were then conducted.

\section{STATISTICAL ANALYSIS}

\section{A. Characteristics of Subjects and Reliability Analysis Results}

Frequency analysis was conducted to examine social characteristics of subjects. Of 853 college students, 431 $(50.5 \%)$ were Korean students and $422(49.5 \%)$ were Chinese students. There were $558(65.4 \%)$ females and 295 (34.6\%) males.

\section{B. Differences in consciousness Level According to HCI Over-Engagement level}

Regarding overall consciousness level in a scale of 5.0, Korean students showed a level of 2.647 and Chinese students showed a level of 3.180. According to consciousness level, subjective perception of Korean college students was the highest at a level of 2.881 as shown in Table- II, followed by self-awareness at 2.768 and sensory perception at 2.306. Self-awareness had a level of 3.342 while subjective perception had a level of 3.220 and sensory perception had a level of 2.908 .

Table- II: Mean and standard deviation of perception level

\begin{tabular}{|c|c|c|c|}
\hline \multicolumn{2}{|c|}{ Division } & Average & SD \\
\hline \multirow{4}{*}{ Korean } & Sensory perception & 2.306 & .788 \\
\cline { 2 - 4 } & Subjective perception & 2.881 & .601 \\
\cline { 2 - 4 } & Self-awareness & 2.768 & .689 \\
\cline { 2 - 4 } & Total & 2.647 & .617 \\
\hline \multirow{4}{*}{ Chinese } & Sensory perception & 2.908 & .707 \\
\cline { 2 - 4 } & Subjective perception & 3.220 & .557 \\
\cline { 2 - 4 } & Self-awareness & 3.342 & .634 \\
\cline { 2 - 4 } & Total & 3.180 & .551 \\
\hline
\end{tabular}

As a result of reliability analysis, sensory perception had a Cronbach's $\alpha$ value of .741 , subjective perception had a Cronbach's $\alpha$ value of .636 , and self-awareness had a Cronbach's $\alpha$ value of .681. This indicates that the method of analyzing effects on the three consciousness levels from Human Computer Interface ( $\mathrm{HCI}$ ) point of view is highly reliable. The classification of questions is also very reliable.

\section{Impact of Consciousness level on Internet HCI Over-Engagement}

An independent sample t-test was conducted to determine the level of perception by country. 
As a result, there were significant differences in sensory perception, subjective perception, and self-awareness between Korean and Chinese college students. For sensory perception, Chinese college students showed a level of 2.908 and Korean college students showed a level of 2.306. For subjective perception, Chinese college students showed a level of 3.220 and Korean college students showed a level of 2.881. For self-awareness, Chinese college students showed a level of 3.342 and Korean college students showed a level of 2.768. There were significant differences in sensory perception, subjective perception, and self-awareness levels between Korean college students and Chinese college students as shown in Table- III.

Table- III: Mean and standard deviation of perception level

\begin{tabular}{|c|c|c|c|c|c|}
\hline \multicolumn{2}{|c|}{ Variable } & Frequency & Average & SD & $\mathrm{t}$ value \\
\hline \multirow{2}{*}{$\begin{array}{c}\text { sensory } \\
\text { perception }\end{array}$} & Korean & 431 & 2.306 & .788 & \multirow{2}{*}{$-11.738^{* * * *}$} \\
\hline & Chinese & 422 & 2.908 & .707 & \\
\hline \multirow{2}{*}{$\begin{array}{l}\text { subjective } \\
\text { perception }\end{array}$} & Korean & 431 & 2.881 & .601 & \multirow{2}{*}{$-8.517^{\text {**** }}$} \\
\hline & Chinese & 422 & 3.220 & .557 & \\
\hline \multirow{2}{*}{$\begin{array}{c}\text { self-aware } \\
\text { ness }\end{array}$} & Korean & 431 & 2.768 & .689 & \multirow{2}{*}{$-12.658^{* *}$} \\
\hline & Chinese & 422 & 3.342 & .634 & \\
\hline
\end{tabular}

\section{PERCEPTUAL LEVELS OF HCI OVER-ENGAGEMENT}

\section{A. Sensory Perception}

The When examining the frequency of sensory perception in college students, for "I sleep during work hours due to internet use", Korean students showed 'Agree' frequency of $8.8 \%$ and 'Strongly agree' frequency of $2.6 \%$ while Chinese students showed 'Agree' frequency of $14.5 \%$ and 'Strongly agree' frequency of $5.7 \%$. Thus, Chinese students replied 'Agree' more frequently. For 'I feel good and excited due to internet use", Korean students showed 'Agree' frequency of $11.1 \%$ and 'Strongly agree' frequency of $2.3 \%$ while Chinese students showed 'Agree' frequency of 30.1\% and 'Strongly agree' frequency of $6.4 \%$. For "I feel irritated when my needs are not met during internet use", Korean students showed 'Agree' frequency of $13.9 \%$ and 'Strongly agree' frequency of $3.5 \%$ while Chinese students showed 'Agree' frequency of $33.6 \%$ and 'Strongly agree' frequency of $10.0 \%$. For "I feel restless and nervous without internet use", Korean students showed 'Agree' frequency of $7.7 \%$ and 'Strongly agree' frequency of $2.8 \%$ while Chinese students showed 'Agree' frequency of $13.5 \%$ and 'Strongly agree' frequency of $3.6 \%$. Thus, in sensory perception, more Chinese students replied with 'Agree' and 'Strongly agree' than Korean students as shown in Table- IV.

Table- IV: HCI over-engagement sensory perception of Korean and Chinese students

\begin{tabular}{|c|c|c|c|c|c|c|c|c|c|c|c|}
\hline \multirow{2}{*}{\multicolumn{2}{|c|}{ Variable }} & \multicolumn{2}{|c|}{$\begin{array}{l}\text { Strongly } \\
\text { disagree }\end{array}$} & \multicolumn{2}{|c|}{ Disagree } & \multicolumn{2}{|c|}{ Neutral } & \multicolumn{2}{|c|}{ Agree } & \multicolumn{2}{|c|}{$\begin{array}{c}\text { Strongly } \\
\text { agree }\end{array}$} \\
\hline & & $\begin{array}{l}\text { Frequ } \\
\text { ency }\end{array}$ & $\%$ & $\begin{array}{c}\text { Freque } \\
\text { ncy }\end{array}$ & $\%$ & $\begin{array}{c}\text { Freque } \\
\text { ncy }\end{array}$ & $\%$ & $\begin{array}{c}\text { Freque } \\
\text { ncy }\end{array}$ & $\%$ & $\begin{array}{l}\text { Frequ } \\
\text { ency }\end{array}$ & $\%$ \\
\hline \multirow{2}{*}{ (1) } & Korean & 121 & 28.1 & 152 & 35.3 & 109 & 25.3 & 38 & 8.8 & 11 & 2.6 \\
\hline & Chinese & 70 & 16.6 & 143 & 33.9 & 124 & 29.4 & 61 & 14.5 & 24 & 5.7 \\
\hline \multirow{2}{*}{ (2) } & Korean & 104 & 24.1 & 140 & 32.5 & 129 & 29.9 & 48 & 11.1 & 10 & 2.3 \\
\hline & Chinese & 19 & 4.5 & 77 & 18.2 & 172 & 40.8 & 127 & 30.1 & 27 & 6.4 \\
\hline (3) & Korean & 101 & 23.4 & 127 & 29.5 & 128 & 29.7 & 60 & 13.9 & 15 & 3.5 \\
\hline
\end{tabular}

\begin{tabular}{|c|c|c|c|c|c|c|c|c|c|c|}
\hline Chinese & 26 & 6.2 & 61 & 14.5 & 151 & 35.8 & 142 & 33.6 & 42 & 10.0 \\
\hline
\end{tabular}

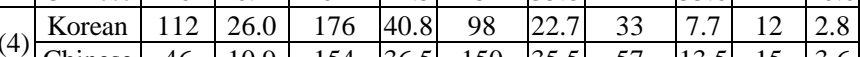

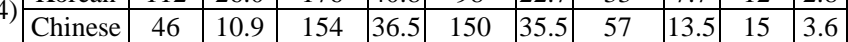

These results suggest that perceptual and emotional level of consciousness can change in the form of nerve impulse that is transmitted to the brain. It influences Chinese college students more than Korean college students.

\section{B. Subjective Perception}

Analysis of subjective perception of Korean college students and Chinese college students was also conducted. For "Grades dropped", Korean students showed 'Agree' frequency of $26.4 \%$ and 'Strongly agree' frequency of $4.2 \%$ while Chinese students showed 'Agree' frequency of $34.8 \%$ and 'Strongly agree' frequency of $11.6 \%$. For "I cannot do other things without internet use", Korean students showed 'Agree' frequency of $30.9 \%$ and 'Strongly agree' frequency of $10.2 \%$ while Chinese students showed 'Agree' frequency of $37.9 \%$ and 'Strongly agree' frequency of $19.0 \%$. For "I tell myself I will stop but continue", Korean students showed 'Agree' frequency of $18.8 \%$ and 'Strongly agree' frequency of $17.2 \%$ while Chinese students showed 'Agree' frequency of $22.3 \%$ and 'Strongly agree' frequency of $19.7 \%$. As shown in Table- V, for "I fail to do planned things", Korean students showed 'Agree' frequency of 3.9\% and 'Strongly agree' frequency of $0.7 \%$ while Chinese students showed 'Agree' frequency of $7.3 \%$ and 'Strongly agree' frequency of $0.9 \%$. For "I initially underestimate my time of internet use", Korean students showed 'Agree' frequency of $24.6 \%$ and 'Strongly agree' frequency of $5.1 \%$ while Chinese students showed 'Agree' frequency of $38.4 \%$ and 'Strongly agree' frequency of $10.2 \%$. For "I always think of reducing time for internet use", Korean students showed 'Agree' frequency of $26.0 \%$ and 'Strongly agree' frequency of $13.7 \%$ while Chinese students showed 'Agree' frequency of $25.1 \%$ and 'Strongly agree' frequency of $8.8 \%$. For subjective perception, Chinese college students showed higher level than Korean college students. For "I always think of reducing time for internet use", the level was higher in Korean students than that in Chinese students.

Table- V: HCI over-engagement subjective perception of Korean and Chinese students

\begin{tabular}{|c|c|c|c|c|c|c|c|c|c|c|}
\hline \multirow[b]{2}{*}{ Variable } & \multicolumn{2}{|c|}{$\begin{array}{l}\text { Strongly } \\
\text { disagree }\end{array}$} & \multicolumn{2}{|c|}{ Disagree } & \multicolumn{2}{|c|}{ Neutral } & \multicolumn{2}{|c|}{ Agree } & \multicolumn{2}{|c|}{\begin{tabular}{|c|}
$\begin{array}{c}\text { Strongly } \\
\text { agree }\end{array}$ \\
\end{tabular}} \\
\hline & $\begin{array}{l}\text { Fre } \\
\text { que } \\
\text { ncy }\end{array}$ & $\%$ & $\begin{array}{l}\text { Fre } \\
\text { que } \\
\text { ncy }\end{array}$ & $\%$ & $\begin{array}{l}\text { Fre } \\
\text { que } \\
\text { ncy }\end{array}$ & $\%$ & $\begin{array}{l}\text { Fre } \\
\text { que } \\
\text { ncy }\end{array}$ & $\%$ & $\begin{array}{l}\text { Fre } \\
\text { que } \\
\text { ncy }\end{array}$ & $\%$ \\
\hline
\end{tabular}

\begin{tabular}{l|c|c|c|c|c|c|c|c|c|c|c|}
\hline & Korean & 51 & 11.8 & 118 & 27.4 & 132 & 30.6 & 112 & 26.0 & 18 & 4.2 \\
\cline { 2 - 11 }
\end{tabular}

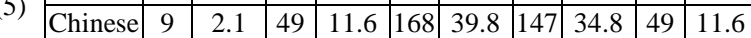

\begin{tabular}{l|l|l|l|l|l|l|l|l|l|l|l|l|}
\hline & Korean & 47 & 10.9 & 65 & 15.1 & 142 & 32.9 & 133 & 30.9 & 44 & 10.2 \\
\cline { 2 - 10 } & Chinese & 7 & 1.7 & 51 & 12.1 & 124 & 29.4 & 160 & 37.9 & 80 & 19.0 \\
\hline
\end{tabular}

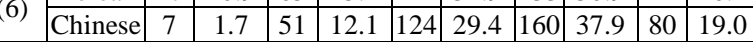

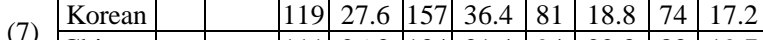

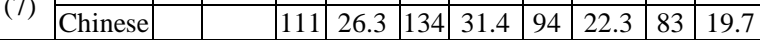

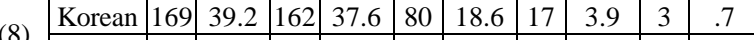

\begin{tabular}{|l|l|l|l|l|l|l|l|l|l|l|l|}
\hline & $8)$ \\
\cline { 2 - 13 }$y$
\end{tabular}

\begin{tabular}{l|c|c|c|c|c|c|c|c|c|c|c|}
\hline & Korean & 64 & 14.8 & 94 & 21.8 & 145 & 33.6 & 106 & 24.6 & 22 & 5.1 \\
\hline
\end{tabular}

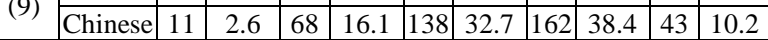

\begin{tabular}{|c|c|c|c|c|c|c|c|c|c|}
\hline Korean & 87 & 20.2 & 173 & 40.1 & 112 & 26 & & & \\
\hline Chinese & 76 & 18.0 & 203 & 48.1 & $10 t$ & & & & \\
\hline
\end{tabular}




\section{Self-Swareness}

Regarding self-awareness, for "I control my internet use time", Korean students showed 'Disagree' frequency of $31.1 \%$ and 'Strongly disagree' frequency of $28.1 \%$ while Chinese students showed 'Disagree' frequency of $28.2 \%$ and 'Strongly disagree' frequency of 7.8\%. For "I do not use the internet until I am tired", Korean students showed 'Disagree' frequency of $12.1 \%$ while Chinese students showed 'Disagree' frequency of 7.6\%. For "I do planned tasks even with internet use", Korean students showed 'Disagree' frequency of $15.3 \%$ and 'Strongly disagree' frequency of 9.0\% while Chinese students showed 'Disagree' frequency of $6.6 \%$ and 'Strongly disagree' frequency of $1.2 \%$. For "I am not nervous without internet use", Korean students showed 'Disagree' frequency of $36.7 \%$ and 'Strongly disagree' frequency of $24.4 \%$ while Chinese students showed 'Disagree' frequency of $22.7 \%$ and 'Strongly disagree' frequency of $5.7 \%$. As shown in Table- VI, Korean college students integrated their feelings with self-awareness better regardless of physical or social situation by properly controlling internet use time and performing planned work than Chinese college students.

Table- VI: HCI over-engagement self-awareness of Korean and Chinese students

\begin{tabular}{|c|c|c|c|c|c|c|c|c|c|c|c|}
\hline \multirow{2}{*}{\multicolumn{2}{|c|}{ Variable }} & \multicolumn{2}{|c|}{$\begin{array}{l}\text { Strongly } \\
\text { disagree }\end{array}$} & \multicolumn{2}{|c|}{ Disagree } & \multicolumn{2}{|c|}{ Neutral } & \multicolumn{2}{|c|}{ Agree } & \multicolumn{2}{|c|}{$\begin{array}{c}\text { Strongly } \\
\text { agree }\end{array}$} \\
\hline & & & & Fre & & Fre & & & & Fre & \\
\hline \multirow{3}{*}{ (11) } & & 121 & 281 & 134 & 311 & 98 & 22 & & & 10 & 23 \\
\hline & & & & & & & & & & & \\
\hline & Chine & 33 & 7.8 & 119 & 28.2 & 149 & 35.3 & & 22.0 & 27 & 6.4 \\
\hline \multirow{2}{*}{ (12) } & Korean & & & 52 & 12.1 & 209 & 48.5 & 128 & 29.7 & 42 & 9.7 \\
\hline & Chinese & & & 32 & 7.6 & 170 & 40.3 & 174 & 41.2 & 46 & 10.9 \\
\hline \multirow{2}{*}{ (13) } & Korean & 39 & 9.0 & 66 & 15.3 & 169 & 39.2 & 130 & 30.2 & 27 & 6.3 \\
\hline & Chinese & 5 & 1.2 & 28 & 6.6 & 85 & 20.1 & 199 & 47.2 & 105 & 24.9 \\
\hline \multirow{2}{*}{ (14) } & Korean & 105 & 24.4 & 158 & 36.7 & 119 & 27.6 & 42 & 9.7 & 7 & 1.6 \\
\hline & Chinese & 24 & 5.7 & 96 & 22.7 & 176 & 41.7 & 96 & 22.7 & 30 & 7.1 \\
\hline
\end{tabular}

\section{CONCLUSION}

In this study, using the Adult Internet Self-Assessment Scale, effects of human computer interface on three consciousness levels of Korean and Chinese college students were analyzed. As a result of reliability analysis, reclassification of self-diagnostic questionnaire items according to the level of consciousness was also very reliable, similar to a previous study. Chinese college students were found to be more influenced than Korean students in terms of perceptual and emotional consciousness level, subjective consciousness level, and self-awareness level according to HCI over-engagement. In particular, in the case of self-awareness, Korean students were found to be able to integrate with the feeling of self-awareness better than Chinese students regardless of physical or social situation.

In summary, development of items measuring inner compatibility according to three consciousness levels is reasonable when perceptual and emotional consciousness levels, subjective consciousness level, and self-awareness level are separated. This is because HCI over-engagement affects each layer of the human state of consciousness. This implies that the interpretation of HCI dysfunction should be interpreted in terms of over-engagement. Results of this study also confirms that various levels of consciousness are influenced by HCI over-engagement differently.

\section{REFERENCES}

1. M. M. Skoric, L. L. C. Toe, R. L. Neo, "Children and Video Games: Addiction, Engagement, and Scholastic Achievement" CyberPsychology \& Behavior [Internet], 12(5), 567-72, 2009.

2. G. C. Patton, C. A. Olsson, V. Skirbekk, R. Saffery, M. E. Wlodek, P. S. Azzopardi, M. Stonawski, B. Rasmussen, E. Spry, K. Francis, et al., "Adolescence and the next generation" Nature [Internet], 554, 458-66, 2018.

3. R. E. Dahl, N. B. Allen, L. Wilbrecht, A. B. Suleiman, "Importance of investing in adolescence from a developmental science perspective" Nature [Intenet], 554, 441-50, 2018.

4. C. Seife, Decoding the Universe: How the New Science of Information Is Explaining Everything in the Cosmos, from Our Brains to Black Holes, Penguin Books, 2007.

5. E. T. Jaynes, "Information Theory and Statistical Mechanics" Physical Review Journals [Internet], 106(4), 620-30, 1957.

6. N. J. Cerf, C. Adami, "Negative Entropy and Information in Quantum Mechanics" Physical Review Letters [Internet], 79(26), 5194-7, 1997.

7. E. R. John, "A Theory of Consciousness" Current Directions in Psychological Science [Internet], 12(6), 244-50, 2003.

8. J. R. Battista, "The Science of consciousness" The Stream of Consciousness, 55-87, 1978.

9. G. Tononi, M. Boly, M. Massimini, C. Koch, "Integrated information theory: from consciousness to its physical substrate" Nature Reviews Neuroscience, 17, 450-461, 2016.

10. J. Lee, H. Park, C. Lim, "An Analysis of Introvert and Extrovert Problems according to the Patterns of Internet Addiction in University Students" IJPHRD, 9(8), 933-8, 2018.

11. H. Park, C. Lim, J. Lee, "A Study of a Diagnosis and Examination Questionnaire for Forming Inner Compatibility Indicators" IJPHRD, 9(9), 1193-200, 2018.

\section{AUTHORS PROFILE}

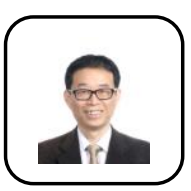

Jae-Yong Lee is a professor of UAV(unmanned aerial vehicle) department at Hanseo University in Republic of Korea (2000 currently), with a bachelor's degree, a master's degree, and a doctorate degree in computer science; and a master's degree in psychology. His interests are HCI, psychology of programming, unmanned mobile interaction, and artificial intelligence. He is mainly studying the methodology of human-computer interaction which influences the depth of the human inner factors; and the effective ways of programming learning and teaching, processing at the view of HCI.

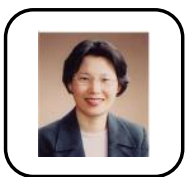

Hae-Ri Park is a professor at Hanseo University, Department of Public Health, Shin Sung University. His master's degree has an advanced degree and his doctorate has social welfare. Also She is Running the Home Care Elderly Facility. Her master thesis is "The relationship between male senior citizens' sex life and depression". And her doctoral thesis is "A study on Problem Behaviors of the Adolescents of Grandparent-Grandchild Family." She has also published many papers in the fields of sociology, health sciences and social welfare.

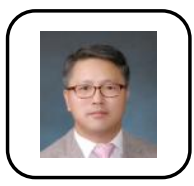

Cheong-Hwan Lim is a Professor of radiological science and health medicine department at Hanseo University in Republic of Korea (2001 currently). Currently serving as chairman of the Korea Radiological Science Association and chairman of the editorial committee (2016 currently). 